\title{
Acute Ethanol Effects on Focal Cerebral Ischemia in Nonfasted Rats
}

\author{
Yong-Jie Zhao, Guo-Yuan Yang, and Edward F. Domino
}

\begin{abstract}
Focal cerebral ischemia was induced in a rat model of middle cerebral artery occlusion. Three groups of adult male Sprague-Dawley rats, given food and water ad libitum, were subjected to $4 \mathrm{hr}$ of middle cerebral artery occlusion. All were given vehicle control and ethanol pretreatments intraperitoneally $1 \mathrm{hr}$ before. Mean ipsilateral brain water content in the control, $2 \mathrm{~g} / \mathrm{kg}$ ethanol, and $2 \mathrm{~g} / \mathrm{kg}$ ethanol + insulin-treated groups showed: ischemia core: $81.1 \%, 82.5 \%$, and $80.9 \%$; intermediate zone: $81.0 \%, 81.9 \%$, and $80.3 \%$; and outer zone: $80.3 \%, 81.3 \%$, and $80.1 \%$, respectively. Brain $\mathrm{Na}^{+}$and $\mathrm{K}^{+}$content in these groups paralleled the water content. In addition to significantly $(\rho<0.05)$ more brain edema, the $2 \mathrm{~g} / \mathrm{kg}$ ethanol-treated animal group also had significant hyperglycemia. In contrast, the 2 $\mathrm{g} / \mathrm{kg}$ ethanol + insulin-treated animals were normoglycemic and had ischemic, intermediate, and outer zone $\mathrm{Na}^{+}, \mathrm{K}^{+}$, and $\mathrm{Cl}^{-}$levels comparable with the control group $(p>0.05)$. These results stress the importance of measuring and controlling plasma glucose levels in the in vivo studies of the neurotoxic effects of acute ethanol.

Key Words: Ethanol, Hyperglycemia, Insulin, Ischemia.
\end{abstract}

$\mathbf{I}$ $\mathrm{N}$ VIEW of the widespread misuse of ethanol, it is surprising so little is known about its effects on acute brain ischemia. There is also a lack of data on whether the hyperglycemia that results when ethanol is administered to nonfasted animals contributes to acute brain injury. The goal of the present research was to determine the effects acute ethanol intoxication on focal cerebral ischemia in nonfasting rats in a highly reproducible model of middle cerebral artery occlusion (MCAO) ${ }^{1-3}$ The experiments were designed to mimic a human scenario of two ethanol intoxicated males and one male teetotaler (i.e., a person who does not drink ethanol). All three had meals before an identical MCAO. The question to be answered was which had more or less brain edema when examined $4 \mathrm{hr}$ later. The hypothesis tested is that ethanol-induced hyperglycemia in vivo contributes, in part, to its acute neurotoxicity. Brain edema is a major complication and cause of death after a stroke. The development of ischemic brain edema is related to an increase of water and $\mathrm{Na}^{+}$and a decrease of $\mathrm{K}^{+}$. Edema formation was chosen because this is a major indicator of quality of survival in patients with brain ischemia.

From the Departments of Pharmacology and Surgery (Neurosurgery), University of Michigan, Ann Arbor, Michigan.

Received for publication December 2, 1996; accepted February 11, 1997

This study was supported by the Psychopharmacology Research Fund 361024.

Reprint requests: Edward F. Domino, M.D., Department of Pharmacology, University of Michigan, Ann Arbor, MI 48109-0632.

Copyright (c) 1997 by The Research Society on Alcoholism.

\section{MATERIALS AND METHODS}

\section{Experimental Protocol}

This study was approved by the University of Michigan Committee on the Use and Care of Animals. Twenty-one adult male Sprague-Dawley rats weighing 230 to $300 \mathrm{~g}$ (Charles River, Portage, MI) were randomly divided into three groups to undergo MCAO for $4 \mathrm{hr}$. They were on a 0700 to 1900 light and 1900 to 0700 dark cycle on a standard rodent diet and water ad libitum. They were pretreated $60 \mathrm{~min}$ before MCAO as follows: group 1 were controls who received $5 \%$ glucose solution $10 \mathrm{mg} / \mathrm{kg}$ ip; group 2 received $20 \%$ ethanol in $5 \%$ glucose solution in a dose of $2 \mathrm{~g} / \mathrm{kg}$ ip; and group 3 received $20 \%$ ethanol in a dose of $2 \mathrm{~g} / \mathrm{kg}$ ip +insulin. Small doses of insulin (IU) were given intravenously to maintain normoglycemia during MCAO. During all experiments, physiological parameters were monitored and maintained in the normal range. Local cerebral blood flow (CBF) was measured through the surface of the cortex using a laser Doppler flowmeter monitor (Vasamedics, Inc., St. Paul, MN) equipped with a small caliber probe of $0.7 \mathrm{~mm}$ in diameter (P-433, Vasamedics). Rectal temperature was measured by a thermometer (YSI, model 73A; Yellow Springs Instrument Co., Yellow Springs, $\mathrm{OH}$ ). The temperature was carefully regulated by heating lamp and heating pad to maintain $37^{\circ} \mathrm{C}$. After $4 \mathrm{hr}$ of MCAO, each animal was killed and brain samples measured for water and ion content. The $100 \mathrm{units} / \mathrm{ml}$ of insulin was diluted with $0.9 \% \mathrm{NaCl}$ to a 1 unit/ml solution.

\section{Rat MCAO Suture Model}

Anesthesia was induced by inhalation with $5 \%$ isoflurane in 0.7 liters/ min: $\mathrm{O}_{2}$ /air gas mixture. After tracheal intubation, the lungs were mechanically ventilated to maintain the $\mathrm{PaO}_{2} 90 \mathrm{~mm} \mathrm{Hg}$ or above. Anesthesia was continued with $1.5 \%$ isoflurane. The femoral artery was cannulated with PE-50 tubing to allow continuous monitoring of arterial blood pressure and sampling of arterial gases, blood $\mathrm{pH}$, and blood glucose. Arterial blood pressure was maintained above $90 \mathrm{~mm} \mathrm{Hg}$ by adjusting the isoflurane concentration. MCAO was produced as described previously. ${ }^{1-3}$ Briefly, under an operating microscope, the left common carotid artery was exposed through a midline incision. The branches of the external carotid artery (ECA) were isolated and coagulated along with the terminal lingual and maxillary artery branches. The internal carotid artery (ICA) was then isolated and its extracranial branch, the pterygopalatine artery, was ligated close to its origin. The ICA remained patent. A 3-cm length of 3-0 nylon suture with a slightly enlarged and rounded tip was introduced into the transected lumen of the ECA and gently advanced from the ECA into the ICA. The distance from the tip of the suture to the bifurcation of the common carotid artery was 19 to $20 \mathrm{~mm}$ in these rats.

\section{CBF Measurement}

Laser Doppler flow was determined at two cortical sites. Point A was placed $6 \mathrm{~mm}$ lateral in the contralateral hemisphere, and point $B$ was placed $6 \mathrm{~mm}$ lateral in the ipsilateral ischemic hemisphere. Both sites were $1.5 \mathrm{~mm}$ posterior to the bregma. After mounting the rat in a stereotaxic frame, the skull was exposed through a midline skin incision. Two $2.0 \mathrm{~mm}$ holes were drilled such that a thin bone layer could be carefully removed to prevent injury to the cortex. The dura maintained intact. The probe was held in a micromanipulator and stereotactically advanced to gently touch 


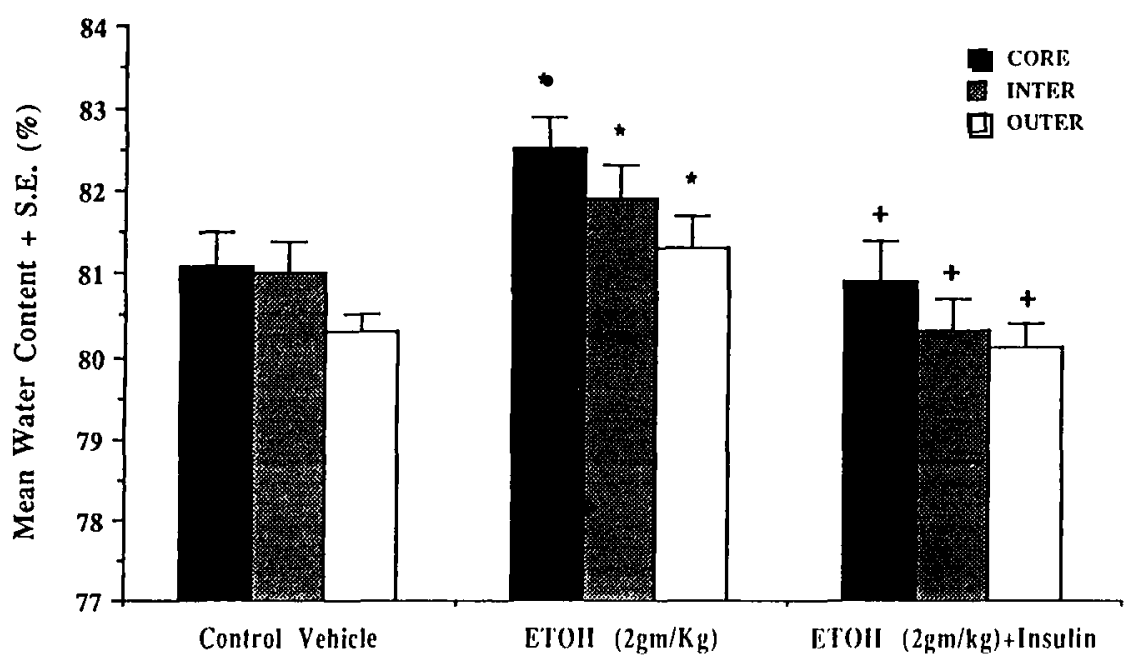

Fig. 1. Effect of ethanol (ETOH) on mean water content of ischemic brain tissue after MCAO. The mean water content $+\mathrm{SE}$ is plotted for the ipsilateral brain for the ischemic core and inner and outer penumbra zones. The groups to the left are control vehicle rats made ischemic. A dose of $2 \mathrm{~g} / \mathrm{kg}$ ip of ethanol $1 \mathrm{hr}$ before produced a statistically significant increase ( $p<0.05)$ in brain edema that was reversed to control ischemic levels $(p<0.05)$ in the third group of rats given $2 \mathrm{~g} / \mathrm{kg}$ ip of ethanol $1 \mathrm{hr}$ before +0.25 to 0.5 units $/ \mathrm{kg}$ of insulin to maintain normoglycemia. The latter group was statistically significantly different $(+p<0.05)$ from the ethanol alone-treated group. In this and subsequent figures, atl rats were nonfasted before $4 \mathrm{hr}$ MCAO. the intact dura mater. To obtain a clear optical medium between the flow probe and the cortex, and to maintain the brain temperature at $37^{\circ}$ to $37.5^{\circ} \mathrm{C}$, warmed $0.9 \% \mathrm{NaCl}$ was slowly perfused around the probe during the experiment. Ten minutes of stable baseline flow readings were obtained before occlusion. Then, MCAO was produced and the digital display of $\mathrm{CBF}$ recorded. The $\mathrm{CBF}$ values were calculated and expressed as percentage of baseline values (milliliters per 100 grams per minute). If $\mathrm{CBF}$ was not maintained below $35 \mathrm{ml} / 100 \mathrm{~g} / \mathrm{min}$ during occlusion, the animal was excluded from the study.

\section{Water, $\mathrm{Na}^{+}, \mathrm{K}^{+}$, and $\mathrm{Cl}^{-}$Content}

Samples were removed using 7 and $10 \mathrm{~mm}$ cork borers from the core, intermediate, and outer zones of the ischemic cerebral cortex and the corresponding areas of the contralateral nonischemic cortex. ${ }^{4,5}$ Briefly, the core was defined as the lateral cortex directly underlying the occluded portion of the middle cerebral artery. The intermediate zone was the ring of brain tissue that surrounded the core, whereas the outer zone was the remaining cortical tissue. The tissue samples were weighed with $0.0001 \mathrm{mg}$ precision to obtain each wet weight (W). Samples were then dried in an oven (Blue M Electric Co., Blue Island, IL) at $100^{\circ} \mathrm{C}$ for $24 \mathrm{hr}$ and reweighed to obtain their dry weight $(D)$. The water content was expressed as percentage wet weight and was calculated as $(W-D) / W \times 100$. The dehydrated section was digested in $1 \mathrm{ml}$ of $1 \mathrm{~N}$ nitric acid for 1 week. Then a $0.2 \mathrm{ml}$ aliquot was removed and diluted to $2 \mathrm{ml}$ with deionized water and $3 \mathrm{mM} \mathrm{CsCl} 2$ solution. The $\mathrm{Na}^{+}$and $\mathrm{K}^{+}$contents were measured with a sample of this solution by atomic absorption spectroscopy (IL943TM Automatic Flame Photometer, Instrumentation Laboratory, Inc., Lexington, MA). Flame conditions and detection wavelengths were optimized for sensitivity and linearity. The $\mathrm{Cl}^{-}$content was measured by a digital chloridometer (Haakebuchler Instruments, Inc., Saddleblock, NJ).

\section{Plasma Glucose}

Plasma glucose was determined using a Glucometer II (Miles Laboratories, Inc., Elkhart, IN).

\section{Statistical Analysis}

All of the data were expressed as the mean \pm SE. Statistical differences among groups were determined using ANOVA and the Dunnett $t$ test. Probability values of $<5 \%$ were considered significant.

\section{RESULTS}

\section{Physiological and Pharmacological Parameters}

Animals were excluded from this study if their physiological parameters (with the exception of plasma glucose) were not in the normal range during the experiment. ANOVA failed to reveal a difference between the groups in every parameter measured (mean arterial blood pressure, rectal temperature, arterial $\mathrm{pH}, \mathrm{pCO}_{2}, \mathrm{pO}_{2}, \mathrm{HCO}_{3}{ }^{-}$, and hematocrit) except plasma glucose. The group of nonfasting animals treated with $2 \mathrm{~g} / \mathrm{kg}$ of ethanol had a greater plasma glucose level than the nonfasting controls. All animals had normal pre- and postischemia blood gases $\left(\mathrm{pO}_{2}\right.$, $\mathrm{pCO}_{2}$, and $\mathrm{HCO}_{3}{ }^{-}$), $\mathrm{pH}$, hematocrit, plasma osmolarity, and rectal temperatures. Mean arterial blood pressure was normal before and after MCAO, with no difference among the various groups.

\section{$C B F$}

Introduction of the suture to occlude the blood supply to the territory of the left middle cerebral artery produced an equal fall $(\sim 12 \%$ of control) in relative surface blood flow in all three groups. The mean percentage of baseline CBF in the contralateral hemisphere was comparable, remaining $\sim 100 \%$ in all three groups. There were no significant differences in comparable hemispheric CBF among the three ischemic groups $(p>0.05)$.

\section{Changes in Water and Ion Content}

The changes in water content in the core, intermediate, and outer zones of ischemic cortex of all three groups are illustrated in Fig. 1. The water content in the contralateral normal hemisphere of all experimental groups was similar ( $\sim 78$ to $79 \%$ ). However, in the ischemic hemisphere, the nonfasted control group had a water content of $81.1 \pm$ $0.4 \%$ (core), $81.0 \pm 0.4 \%$ (intermediate zone), and $80.3 \pm$ $0.2 \%$ (outer zone). These increases in water in the ischemic 


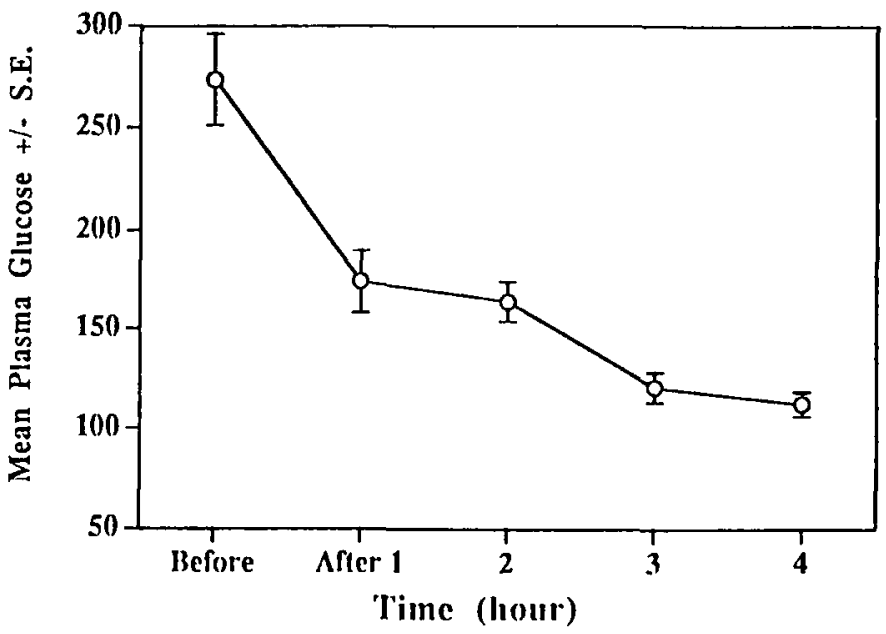

Fig. 2. Plasma giucose levels in ethanol-treated rats given insulin during middle cerebral occlusion. Immediately before intravenous insulin therapy in a dose of 0.25 to 0.5 units $/ \mathrm{kg}$, the nonfasted $2 \mathrm{~g} / \mathrm{kg}$ ip ethanol rats had severe hyperglycemia which, when treated with insulin, were normoglycemic by the end of the $4 \mathrm{hr}$ period of MCAO. In this and Fig. 3, plasma glucose concentrations are in $\mathrm{mg} / \mathrm{dl}$.

hemisphere were statistically significantly greater than in the nonischemic cortexes $(p<0.05)$. The water content in the ischemic hemisphere of the nonfasted animals treated with $2 \mathrm{~g} / \mathrm{kg}$ of ethanol was also significantly increased $(p<$ $0.05)$, compared with the control ischemic group. The third group of nonfasted animals treated with $2 \mathrm{~g} / \mathrm{kg}$ of ethanol were given insulin ( 0.25 to 0.5 units $/ \mathrm{kg}$, iv) to maintain plasma glucose levels normal. In this group, brain edema in the ischemic areas was similar to the control ischemic animals $(p>0.05)$. The water gain of the ischemic brain tissue was accompanied by comparable shifts in $\mathrm{Na}^{+}, \mathrm{K}^{+}$, and $\mathrm{Cl}^{-}$.

\section{Correlation between Brain Edema Formation and Plasma Glucose during $M C A O$}

One group of nonfasting rats was treated with regular insulin in incremental doses of 0.25 units $/ \mathrm{kg}$ iv within $3 \mathrm{~min}$ after occlusion, and another dose as needed to maintain a normal plasma glucose level. The plasma glucose level before and after insulin during MCAO is shown in Fig. 2. Before MCAO, the plasma glucose was $287 \pm 28 \mathrm{mg} / \mathrm{dl}$. After administration of 0.25 to 0.5 units $/ \mathrm{kg}$ iv of insulin, the glucose concentration progressively decreased and was in the normal range after $4 \mathrm{hr}$. Correlation between water content in the ischemic core and levels of plasma glucose is shown in Fig. $3(r=0.76 ; p<0.05)$. Edema formation was significantly less in the rats treated with insulin $(p<0.05)$ that resulted in normal glucose blood levels.

\section{DISCUSSION}

A confounding variable in the present in vivo studies is that isoflurane, oxygen, and air are used to produce general anesthesia for the surgical procedure of MCAO. Thus, one

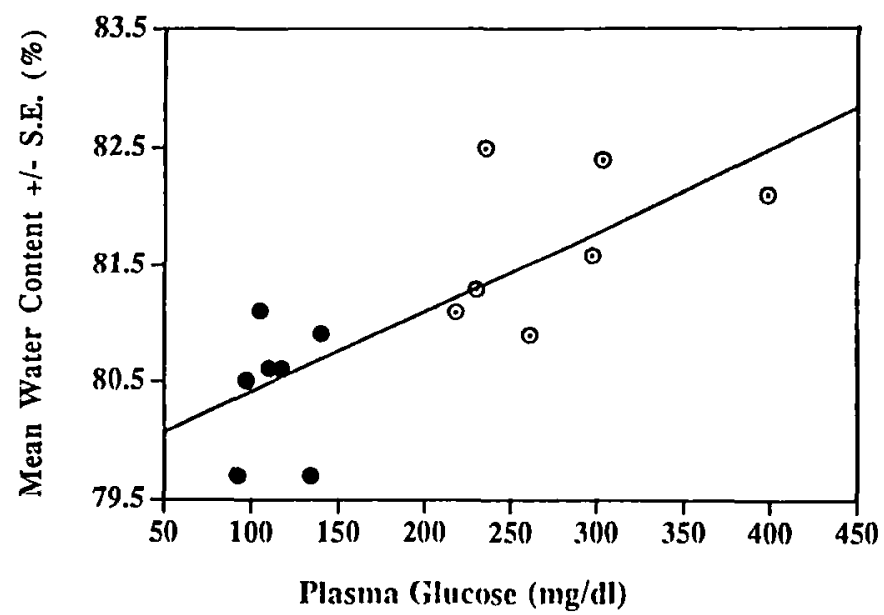

Fig. 3. Relationship between plasma glucose concentration and brain edema. Plasma glucose levels of the control nonfasted (O) and the $2 \mathrm{~g} / \mathrm{kg}$ ethano nonfasted $(\odot)$ rats are plotted on the $x$-axis versus the mean percentage of water content of the core region on the $y$-axis. There is a significant correlation $(r=0.76$, $\rho<0.05)$.

is studying the effects of ethanol plus general anesthesia, compared with the effects of general anesthesia alone on brain ischemia. General anesthesia must be used for ethical reasons. Until more reliable methods are developed for producing MCAO without anesthesia, this variable must be present in research of this type. Depth of anesthesia (with and without the added ethanol) was closely monitored using arterial blood pressure, relief of surgical pain as noted by reflex motor movements, normal arterial blood gases, etc. A period of $4 \mathrm{hr}$ of ischemia was used because such a period of MCAO is known to produce statistically significant increases in brain edema in control ethanol free animals. Furthermore, a small amount of $5 \%$ glucose was used as the vehicle to make certain that the animals were normoglycemic before ethanol administration. Inasmuch as ethanol induces hypothermia, it was very important to maintain normal body temperature, which was measured rectally. It is known that brain temperature is slightly lower than body temperature in MCAO surgically prepared animals, but this was consistent across all of the groups studied. A brain probe to measure brain temperature directly might cause some brain damage and, therefore, was avoided.

One mechanism by which in vivo ethanol worsens brain edema is to enhance blood glucose levels in nonfasted animals. When a group of similarly treated animals were given sufficient insulin to maintain normal glucose levels, ethanol $(2 \mathrm{~g} / \mathrm{kg}$, ip) did not increase brain edema. There is a large literature on the beneficial effects of reduced carbohydrate diet, weight loss, insulin, and mild hypoglycemia on acute brain damage, and the opposite with hyperglycemia. ${ }^{6-20}$ Regional CBF is also decreased during hyperglycemia. $^{21,22}$ On the other hand, hyperglycemia reduces thrombotic infarction induced photochemically in rat parietal cortex. ${ }^{23}$ However, hyperglycemia is usually neurotoxic in vivo. The purpose of the present study was to design an 
experiment that would mimic an in vivo human situation involving relatively large doses of ethanol in which hyperglycemia would probably occur. This was accomplished using nonfasting ethanol-treated rats. As predicted, the control nonfasting ischemic rats had the same degree of edema formation as nonfasting + ethanol $(2 \mathrm{~g} / \mathrm{kg})$ and insulin-treated animals. One possibility is that the hyperglycemic action of ethanol in fed rats caused the enhanced edema formation. Insulin attenuates ischemic brain damage independent of its hypoglycemic effect. ${ }^{16}$ Hence, it may be that insulin alone was brain protective. In a separate study, we have shown that $2 \mathrm{~g} / \mathrm{kg}$ ip of ethanol in fasted rats that are normoglycemic does not enhance brain edema. Therefore, one can conclude that hyperglycemia induced by the $2 \mathrm{~g} / \mathrm{kg}$ dose of ethanol is the mechanism of acute neurotoxicity. However, fasting rats given a larger dose (3 $\mathrm{g} / \mathrm{kg}$ ) of ethanol before induction of ischemia do not have hyperglycemia, but have more severe brain edema compared with control nonethanol-treated animals. ${ }^{24}$ Thus, there is still another mechanism, unrelated to ethanolinduced hyperglycemia, for the deleterious effects of ethanol that remains to be clarified. Ethyl alcohol-induced hyperglycemia is mediated in part via catecholamine release. The mechanism of hyperglycemic brain injury remains to be elucidated, but may involve lactic acidosis and endothelial cell injury. ${ }^{25}$ The results of the present study indicate the importance of maintaining normoglycemia in investigations of ethanol-induced neurotoxicity in vivo. Future studies should also determine, in addition to ethanol-induced brain edema, specific neuronal damage, as well as survival and functional outcome with and without insulin therapy.

\section{REFERENCES}

1. Yang G-Y, Chen SF, Kinouchi H, Chan PH, Weinstein PR: Edema, cation content, and ATPase activity after middle cerebral artery occlusion in rats. Stroke 23, 1331-1336, 1992

2. Kadoya C, Domino EF, Yang GY, Stern JD, Betz AL: Pre-ischemic but not post-ischemic zinc protoporphyrin treatment reduces infarct size and edema accumulation after temporary cerebral ischemia in rats. Stroke 26:1035-1038, 1995

3. Zhao Y, Yang G-Y, Domino EF: Zinc protoporphyrin, zinc ion and protoporphyrin reduce focal cerebral ischemia. Stroke 27:2299-2303, 1996

4. Betz AL, Coester HC: Effect of steroids on edema and sodium uptake of the brain during focal ischemia in rats. Stroke 21:1199-1204, 1990

5. Martz D, Beer M, Betz AL: Dimethylthiourea reduces ischemic brain edema without affecting cerebral blood flow. J Cereb Blood Flow Metab 10:352-357, 1990

6. Candelise L, Landi G, Orazio EN, Bocardi E: Prognostic significance of hyperglycemia in acute stroke. Arch Neurol 42:661-663, 1985

7. Chopp M, Welch KMA, Tidwell CD, Helpern JAA: Global cere- bral ischemia and intracellular $\mathrm{pH}$ during hyperglycemia and hypoglycemial in cats. Stroke 19:1383-1.387. 1988

8. Dietrich WD. Alonso O. Busto R: Moderate hyperglycemia worsens acute blood-brain barrier injury after forebrain ischemia in rats. Stroke 24:111-116, 1993

9. Hoffman WE, Braucher E. Pelligrino DA. Thomas C, Albrecht RF, Miletich DJ: Brain lactate and neurologic outcome following incomplete ischemia in fasted, nonfasted, and glucose-loaded rats. Anesthesiology 72:1045-1050). 1990

10. LeMay DR. Behua L. Zelenock GB. D*Alecy LG: Insulin administration protects neurologic function in cerebral ischemia in rats. Stroke 19:1411-1419, 1988

11. Nedergaard $M$ : Transient focal ischemia in hyperglycemic rats is associated with increased cerebral infarction. Brain Res 408:79-85, 1987

12. Nedergaard M, Diemer NH: Focal ischemia of the rat brain. with special reference to the influence of plasma glucose concentration. Acta Neuropathol 73:131-137, 1987

13. Prado R. Ginsberg MD, Dietrich WD, Watson BD, Busto R: Hyperglycemia increases infarct size in collaterally perfused but not endarterial vascular territories. J Cereb Blood Flow Metab 8:186-192, 1988

14. Pulsinelli WA, Levy DA, Sigsbee B. Scherer P, Plum G: Increased damage after ischemic stroke in patients with hyperglycemia with or without established diabetes mellitus. Am J Med 74:540-544, 1983

15. Pulsinelli WA, Waldman S, Rawlinson D, Plum F: Moderate hyperglycemia augments ischemic brain damage: A neuropathologic study in rat. Neurology 32:1239-1246, 1982

16. Voll $\mathrm{CL}$, Auer RN: Insulin attenuated ischemic brain damage independent of its hypoglycemic effect. J Cereb Blood Flow Metab 11: $1006-1014,1991$

17. Warner DS, Gionet TX, Todd MM, McAlister AM: Insulininduced normoglycemia improves ischemic outcome in hyperglycemic rats. Stroke 23:1775-1781, 1992

18. Warner DS, Smith M-L, Siesjo BK: Ischemia in normo- and hyperglycemic rats: Effects on brain water and electrolytes. Stroke 18:464-471, 1987

19. Welsh FA, Ginsberg MD, Rieder W, Budd WW: Deleterious effect of glucose pretreatment on recovery from diffuse cerebral ischemia in the cat. Stroke 11:355-363, 1980

20. Yip PK, He YY, Hsu MD, Garg N, Marangos P, Hogan EL: Effect of plasma glucose on infarct size in focal cerebral ischemia-reperfusion. Neurology 41:899-905, 1991

21. Duckrow RB, Beard DC, Brennan RW: Regional cerebral blood flow decreases during hyperglycemia. Ann Neurol 17:267-272, 1985

22. Duckrow RB, Beard DC, Brennan RW: Regional cerebral blood flow decreases during chronic and acute hyperglycemia. Stroke 18:52-58, 1987

23. Ginsberg MD, Prado R, Dietrich WD, Busto R, Watson, BD: Hyperglycemia reduces the extent of cerebral infarction in rats. Stroke 18:570-574, 1987

24. Zhao, Y-J, Yang G-Y, Ben-Yoseph O, Ross B, Chenevert TL, Domino EF: Acute ethanol effects on focal cerebral ischemia in fasted rats. Manuscript in preparation, 1997

25. Paljärvi L, Rehncrona S, Söderfeldt B, Olsson Y, Kalimo H: Brain lactic acidosis and ischemic cell damage: quantitative ultrastructural changes in capillaries of rat cerebral cortex. Acta Neuropathol 60:232-240, 1983 